\title{
A CRÍTICA LUKACSIANA AO FASCISMO
}

\section{LA CRÍTICA LUKACSIANA DEL FASCISMO}

\section{THE LUKACSIANA CRITICISM OF FASCISM}

DOI: http://dx.doi.org/10.9771/gmed.v11i2.33232

André Figueiredo Brandão ${ }^{1}$

\begin{abstract}
Resumo: O presente texto tem como objetivo a sistematização da crítica ao fascismo operado por Gyorgy Lukács em sua obra, como guia de estudo das tendências evolutivas de tal fenômeno social. Forma regressiva oriunda da crise das sociedades burguesas maduras, o movimento fascista constitui-se como uma alternativa política irracionalista, retrógrada, anti-humanista e aristocrática que é veiculada pela burguesia como válvula de escape para garantir a continuidade do sociometabolismo capitalista. Seu combate depende de um movimento operário que faça uma contraposição radical às suas características estruturais.
\end{abstract}

Palavras-chave: Lukács, Fascismo, Marxismo.

Resumen: Este artículo tiene como objetivo sistematizar la crítica del fascismo operado por Gyorgy Lukács en su trabajo, como una guía para estudiar las tendencias evolutivas de tal fenómeno social. Una forma regresiva derivada de la crisis de las sociedades burguesas maduras, el movimiento fascista constituye una alternativa política irracionalista, retrógrada, antihumanista y aristocrática que la burguesía transmite como una salida para garantizar la continuidad del sociometabolismo capitalista. Su combate depende de un movimiento obrero que se opone radicalmente a sus características estructurales.

Palabras-clave: Lukács, Fascismo, Marxismo.

Abstract: This paper aims to systematize the criticism of fascism operated by Gyorgy Lukács in his work, as a guide to study the evolutionary tendencies of such social phenomenon. A regressive form stemming from the crisis of mature bourgeois societies, the fascist movement constitutes an irrationalist, retrograde, anti-humanist and aristocratic political alternative that is conveyed by the bourgeoisie as an outlet to ensure the continuity of capitalist sociometabolism. Its combat depends on a workers' movement that radically opposes its structural characteristics.

Keywords: Lukács, Fascism; Marxism.

\section{Por uma delimitação lukacsiana da extrema-direita}

Em meio ao conjunto de contradições conformado após a eclosão da crise do capital de 2008, insurge uma alternativa política que há muito não demonstrava coragem nem capacidade de aglutinação necessárias para se apresentar de maneira relevante: a extrema-direita. Nos últimos tempos, podemos observar o neofascismo ganhando as ruas, formando gangues de perseguição a grupos sociais e políticos minoritários, disputando maciçamente o embate de ideias pela hegemonia da sociedade, constituindo sólidas oposições em diversos países, e até mesmo chegando ao poder, como nos casos de Viktor Orban, na Hungria, e no Brasil, com Jair Bolsonaro. A crise política das democracias burguesas promoveu a abertura para a fascistização do tecido social, o que obriga os teóricos comprometidos com o futuro da classe trabalhadora a promoverem investigações que possibilitem a compreensão de tal fenômeno para o movimento de sua classe. 
Uma sóbria delimitação do fenômeno fascista encontra embargo no modo como frequentemente tal conceito é vulgarizado pelas mais diversas correntes. Como alerta Leandro Konder, a própria esquerda, imbuída de uma concepção taticista da ação política, tornou recorrente o emprego do termo fascista apenas por fins agitativos, utilizando-o indistintamente para referir-se a qualquer figura efetiva ou pretensamente de direita, de forma a esvaziar o seu conteúdo (Cf. KONDER, 1977, p. 4).

Existe também a tese defendida pelos liberais de direita e de esquerda, que equivale experiências tão díspares e antagônicas quanto o regime staliniano e o governo Hitler através do termo totalitarismo, numa clara estratégia de descrédito das experiências socialistas e retirada da responsabilidade e vinculação histórica dos movimentos retrógrados radicais com o liberalismo (Cf. LUKÁCS, 2013, p. 789, 809).

Até mesmo a extrema-direita contemporânea, quando lhe é conveniente, abre mão da reivindicação de movimentos e símbolos políticos da sua história, na medida em que observa o grau de repúdio e aversão popular sobre tais elementos. A tentativa de difundir a ideia de que o nazismo e o fascismo italiano foram governos de esquerda é um exemplo do tipo de revisionismo histórico oportunista que tais agrupamentos são capazes de fazer para ampliar a sua validação no debate público, ao passo que mantêm de maneira sorrateira as suas práticas, interesses de classe, e, inclusive, alguns de seus símbolos e palavras de ordem². Como retrata muito bem a analogia feita por Lukács, os fascistas de hoje "podem sacrificar Hitler e Rosenberg e entrincheirar-se na filosofia de Spengler ou de Nietzsche" (idem, 2007 c, p. 25), ou seja, desfazem-se das suas figuras mais contestadas, mas dão continuidade às suas concepções políticas mais fundamentais.

De todas as ferramentas intelectuais possíveis que poderíamos adotar na intenção de ultrapassarmos esta cortina de fumaça em torno do fascismo produzida por sujeitos políticos tão heterogêneos, o marxismo, por sua composição conceitual privilegiada e seu envolvimento histórico com as mais efetivas contraposições teórico-práticas à extrema-direita no século XX, constitui-se como veículo necessário para perquirirmos tal problemática pelas suas raízes. Partindo deste ponto de vista, a perspectiva inaugurada por Lukács se sobressai pela forma como ressalta a dimensão ontológica do ser social frente às tendências neopositivistas e estruturalistas que, por vezes, tomam conta do marxismo.

O esforço aqui pretendido, em busca da sistematização das indicações contidas na obra do filósofo húngaro acerca das características tendenciais do fenômeno político fascista, conforma um esforço relevante, a fim de promover, como diria Engels, "um guia para o estudo e não uma alavanca destinada a erguer construções à maneira hegeliana" (ENGELS, 1961, p. 283), de forma a habilitar as forças políticas proletárias a produzir uma investigação que capture o movimento efetivo do seu objeto de análise. Deve-se levar em conta, no entanto, a impossibilidade de se pretender elaborar um manual metafísico do comportamento do fascismo em todas as suas manifestações através dos tempos.

Assim, podemos penetrar concretamente nas contraditórias linhas evolutivas do fenômeno fascista, que, por mais retrógrado e hediondo que seja, não se conforma numa volta a idade da pedra. Como afirma o filósofo húngaro, as atrocidades e desumanidades produzidas pelo fascismo só podem ser engendradas num sentido oposto ao primitivo: "numa forma de capitalismo altamente desenvolvido" (LUKÁCS, 2014, p. 154). Para afirmar e explorar tal ponto de vista, a abordagem lukacsiana busca 
compreender a dinâmica do ser social da época em questão, traçando uma linha gradual de formação das suas condições reais de explicitação a partir dos triunfos e dos limites que se seguem da consolidação das sociedades burguesas em seu estado mais maduro.

\section{Contradições da sociedade burguesa e o caminho para o fascismo}

Em seu texto Concepşão aristocrática e concepşão democrática do mundo, Gyorgy Lukács partiu da experiência histórica da Revolução Francesa como cânone, isto é, como experiência modelar para a compreensão de processos históricos congêneres. Na disputa pela vanguarda do processo de ruptura em questão, liberais e revolucionários possuíam interesses de classe e projetos societários em franca contraposição. Para o liberalismo, o lado burguês, hegemônico no processo, a consolidação da nova sociedade, agora sob bases democráticas, deveria apresentar um combate às desigualdades sociais, mas por um viés formalista, a saber, por via da unificação do estatuto jurídico de toda a população, de forma que a expectativa era a de que o indivíduo concebido por tal perspectiva, o bomo economicus, prosperaria e se autoregularia através da dinâmica mercantil. Para os revolucionários, movidos pelos interesses materiais dos sans-culottes e do proletariado em gestação, a realização concreta da democracia perpassaria pelo fim da exploração humana, de modo que a emancipação ensaiada extrapolasse os limites imanentes dos interesses da burguesia (Cf. idem, 2007c, p. 28). Ainda neste transcurso, a perspectiva legitimista, representante da nobreza derrotada na revolução, subsiste em agonia no tecido social, em sua busca da naturalização da hierarquia e das desigualdades sociais que imperam nas sociedades de classes.

$\mathrm{Na}$ chamada primavera dos povos, em junho de 1848, o proletariado em avançada maturação organizou-se para uma investida contra o Estado, em busca de sua segunda emancipação. Em resposta a tal inflexão, as frações da burguesia transitaram de uma postura triunfante, ainda com resquícios progressistas, para uma postura conservadora. A ameaça proletária tornou-se relevante, apresentando o anticomunismo como necessidade prática para a classe dominante. Como corolário ideológico de tais circunstâncias, "a resistência à epistemologia materialista e à dialética materialista está em ligação íntima com a resistência da ideologia burguesa ao socialismo" (idem, 1967, p. 19), uma vez que a explicitação abrangente da realidade social se converteu em uma ameaça para a estabilidade do capitalismo.

Desenvolveu-se nestas circunstâncias a chamada decadência ideológica da burguesia, cuja tendência geral é o abandono de sua anterior preocupação em compreender as verdadeiras forças motrizes da sociedade, pelo temor do esclarecimento das suas contradições, "essa fuga numa pseudo-história construída a bel-prazer, interpretada superficialmente, deformada em sentido subjetivista e místico" (idem, 2010, p. 53). Dentro deste movimento, o fascismo, herdeiro teórico do irracionalismo legitimista que havia perdido força, voltou a ter abertura para uma nova manifestação, ao se consolidar como o apogeu de teorias aristocráticos e irracionalistas fortalecidas em tais circunstâncias.

A rota de desenvolvimento das sociedades burguesas consolidadas ampliou gradativamente o abismo entre as conquistas formais da democracia liberal e as demandas concretas da classe trabalhadora. A tensão entre burgeois e citoyen que parte de tal percurso promoveu a privatização da vida humana (Cf. 
idem, 2007c, p. 30). A vida pública coletiva foi reduzida ao mínimo e desmoralizada, promovendo uma dinâmica de socialização como destruição e mutilação do indivíduo e da sua personalidade. Tal processo pôde encontrar raiz no fenômeno da alienação, que se desdobrou na vida humana desde o momento em que se conformou a cisão social em classes antagônicas, uma vez que:

[...] O poder social, isto é, a força de produção multiplicada que surge pela cooperação dos diferentes indivíduos requerida pela divisão no trabalho, aparece a esses indivíduos [...] não como seu próprio poder unido, mas como uma força alienada que existe fora deles, a qual não sabem de onde vem e a que se destina, que eles, portanto, não podem dominar e que, ao contrário, percorre uma série peculiar de fases e etapas de desenvolvimento independente da vontade e do esforço dos homens, e que até mesmo dirige essa vontade e esse esforço. (MARX; ENGELS, 2009, p. 49)

A suposta autonomia do complexo social adquiriu novo patamar com a consolidação histórica do modo de produção capitalista, no qual toda a dinâmica de produção e reprodução da vida do gênero humano foi subordinada a uma nova lei econômica: a valorização do valor. Tal deslocamento de eixo se pôs na contramão de toda e qualquer luta direta pelo enriquecimento humano-genérico. A unilateralidade da sociedade capitalista promove, por sua vez, uma formação empobrecida para o indivíduo social, cuja realização e construção de uma pretensa personalidade autêntica confundiu-se com "a aquisição das respectivas loções capilares, gravatas, cigarros, automóveis etc.” (LUKÁCS, 2013, p. 798).

Em meio a estas contradições, a incapacidade da esquerda proletária organizar o seu projeto societário, aliada à aposta liberal em demover a sua perspectiva para uma visão cada vez mais insustentável de apologia à reprodução da ordem burguesa - por via de soluções formalistas e de bandeiras cada vez mais deflacionadas - abriu espaço para uma alternativa radicalmente anti-humanista, retrógrada, irracionalista e aristocrática apresentar-se como alternativa possível.

Sem ter contato com o humanismo proletário, a população viu o humanismo liberal assumindo cada vez mais uma versão pautada no ideal de um indivíduo isolado e abstrato, uma espécie de universalização do sujeito burguês, que promovia alternativas utópicas e incapazes de propor soluções concretas aos limites da realpolitik (Cf. idem, 2007c, p. 45). Como alternativa, restou o crescimento de um sentimento cada vez maior de anti-humanismo e relativização da condição da vida dos indivíduos sociais.

Da mesma forma, o progresso liberal dissolveu as pretensões de desenvolvimento das faculdades humanas através da história. O que subsistiu, dentro de uma visão apologética da ordem, seriam, portanto, meros avanços técnicos, não-estruturais (Cf. idem, ibdem, p. 35-36), transformando gradativamente as massas em presa fácil para uma visão cética quanto a qualquer possibilidade de avanço humano, sobrando apenas uma chance mistificada de retorno a um passado imaginário.

A razão, sem explorar as contradições efetivas do real, passa a identificar o reino da burguesia como o reino da razão (Cf. idem, ibdem, p. 42). Em outras palavras, a ciência convergiu para uma dimensão de apologia pura, confundindo sua justiça e correção ao grau de utilidade para a reprodução ampliada do capital (Cf. idem, 2010, p. 51). O saldo que pôde ser manobrado pelos fascistas foi uma proposta de negação radical da razão e o desenvolvimento de uma bandeira profundamente antiintelectualista e anticientífica, tomando o irracionalismo como veículo puro de mobilização das massas. 
A debilidade da contraposição da democracia capitalista por uma democracia concreta e operária impossibilitou uma crítica à esquerda do atual regime em que as eleições burguesas efetivamente procedem com um movimento de manipulação do eleitorado para a condução de representantes de "duzentas famílias" ao parlamento. O acúmulo de contradições do poder levou a falsa constatação de que o afastamento das demandas mais imprescindíveis do povo seria um problema de sua própria capacidade de escolha, um problema da democracia em seu sentido mais profundo, e não um problema da democracia liberal. A saída propagandeada pelos fascistas seria a radicalização do caráter aristocrático do poder político, desta vez regido pelas figuras messiânicas do reacionarismo, como o único horizonte possível para as massas em desespero (Cf. idem, 2007c, p. 32-33).

\section{A consolidação fascista e a captura das massas}

O pessimismo anti-humanista ganha tons elegantes e moralmente superiores quando confrontado com a crise do progressismo vulgar dos liberais. O ceticismo raivoso que parte desta condição passa enxergar abrigo no pseudo-heroísmo dos fascistas, em sua inescrupulosa exploração do desespero das massas. O crescimento das organizações da extrema-direita foi observado com tolerância e complacência pelos governos liberais, uma vez que, para tal perspectiva, o fascismo sempre representou uma reserva política contra a esquerda e o comunismo (idem, 1967, p. 103), sendo uma espécie de válvula de escape, o último recurso a ser convertido como tropa de choque para garantir o redirecionamento da insatisfação dos trabalhadores angustiados e confusos no meio a generalizada crise da ordem mercantil3. Em escala internacional, as grandes potências do mundo capitalista observaram sem nenhuma resistência o crescimento do nazifascismo. Despreocupadas, seu desejo mais forte "era derrubar a União Soviética com o auxílio de Hitler [...]. Só a inescrupulosidade absoluta de Hitler na busca pelo império mundial obrigou-as à intervenção bélica contra ele e à aliança sempre cheia de ressalvas com a União Soviética" (idem, 2013, p. 792).

Como explica Leandro Konder, as células e grupos de extrema-direita, compostas de uma caótica amálgama policlassista, só se viabilizaram como um projeto político capaz de realizar um assalto ao Estado quando se associaram às mais significativas frações da burguesia, sobretudo ao capital financeiro (Cf. KONDER, 1977, p. 44-46). Se a direita significa a expressão política dos interesses burgueses de conservação da propriedade privada e das relações sociais vigentes, e a esquerda, o movimento eminentemente proletário, que busca subverter radical e revolucionariamente tais relações, fica claro para qualquer um que se debruce sobre a história do fascismo que tal perspectiva é uma radicalização da direita, movimento abrupto e escancarado subsidiado pela burguesia em meio a sua crise societária para garantir a reprodução ampliada do valor.

Para convencer as massas angustiadas pela crise a aderirem a tal alternativa, o fascismo busca capturar o sentimento de revolta sincera de grandes contingentes da população insatisfeitos com as contradições da democracia burguesa, mobilizando de forma desonesta este sentimento antissistêmico em gestação (Cf. idem, 2014, p. 168). Aparentemente, é absurdo que ideologias escancaradamente 
demagógicas ascendam ao estatuto de corrente relevante no tecido social, mas foi justamente pela capacidade de se apresentarem como forma de efetivar demandas da população que o fascismo conseguiu se viabilizar (Cf. idem, 2013, p. 506-507). Para tanto, soube pôr em debate — diferentemente dos liberais — os problemas sociais mais agudos vividos pelas massas em seu discurso, ignorando, evidentemente, as raízes e soluções concretas de tais demandas (idem, 1967, p. 39).

Dentro de tal processo de captura dos interesses das massas populares, é na pequena burguesia que o fascismo encontrará o destacamento social mais fértil para a sua adesão (Cf. KONDER, 1977, p. 36). O próprio Marx já compreendia a pequena burguesia como "uma classe de transição, na qual os interesses de duas classes se embotam de uma só vez", promovendo a ilusão presunçosa "de se encontrar acima de toda e qualquer contradição de classe" (MARX, 2011, p. 67) — visão que facilmente pode ser canalizada para servir aos interesses das classes dominantes. O desnorteamento da perspectiva pequenoburguesa é seduzido pelos pontos iniciais de um programa fascista, com pautas genéricas que incluem pequenas melhorias para as camadas populares. Tais pautas, entretanto, são intencionalmente vazias, já que, uma vez o partido fascista chegando ao poder, logo são descartadas (Cf. KONDER, 1977, p. 44).

O principal trunfo fascista para formar nas massas as suas ideias é a manipulação da ontologia do cotidiano no contexto capitalista (Cf. LUKÁCS, 2013, p. 561). Não é preciso ler Nietzsche para desenvolver uma perspectiva ultra-reacionária. O fascismo usa ao seu favor as relações de dominação já vigentes para as fetichizar, como se agruras como a fome e a privação fossem um estímulo para o desenvolvimento da personalidade do sujeito. A ideia de causa é fundamental para mobilizar um indivíduo capturado pelo fascismo, fixando-o em sua particularidade, e, consequentemente, desviando-o de uma pretensão humano-genérica. Deste modo, torna-se natural a brutalidade ante qualquer figura oposicionista, do mesmo modo que se compreende e se teme a possibilidade de ser igualmente brutalizado a qualquer momento, desta vez pelo regime.

As massas mobilizadas pelo fascismo se mantêm fiéis ao regime na medida em que o ideal de causa de ação histórica a ser concretizada ainda mantém sua capacidade de persuasão. Para a concepção de mundo fascista, a história é compreendida como uma contínua corrupção e degradação. A única melhora possível seria oriunda de um processo mítico, um verdadeiro milagre, encarnado por um messias dotado da intuição necessária para executá-lo. Ao se concretizar, tal progresso seria na verdade um regresso: o retorno a certo estado originário da nação, a volta de um passado que nunca existiu (Cf. idem, 2007c, p. 36-37). Assim, a ação necessária para a realização de tal objetivo se torna épica e eis que surge o fetiche pela violência — arrastando tudo e todos que seguem na direção oposta.

Toda essa construção se demonstra coerente com a raiz etimológica da palavra fascismo, uma vez que o vocábulo nos remete aos chamados feixes romanos, analogamente simbolizando um coletivo amorfo, isto é, o que aqui representa as massas populares, reunidas em torno de um líder, uma figura central (Cf. KONDER, 1977, p. 29-30). Esse messianismo em torno da direção do regime vincula-se com o caráter aristocrático do conceito fascista de razão. Negando a possibilidade de universalização da capacidade racional, o fascismo promove uma ideia elitista de gênio, como se a genialidade fosse um dom 
que fantasticamente aparece em algumas figuras humanas, destinadas a realizar o retorno da nação a um passado idílico.

\section{A razão antifascista e a sua práxis necessária}

A perspectiva liberal, preocupada com a apologia à ordem vigente, esvazia a razão, identificando-a como mero respaldo formal à ordem e tolhendo-a da sua dimensão progressista, cuja última expressão burguesa foi a filosofia hegeliana, sobre a qual afirma-se a potência racional presente em todos os indivíduos. A visão hegeliana não se confunde com uma defesa relativista do valor do senso comum corrente. Ela afirma a latência universal das capacidades humanas presentes em todos os seus componentes (Cf. LUKÁCS, 2007c, p. 41-42). Este tipo de perspectiva, eminentemente anti-aristocrática, encontrou a vazão e o interesse material necessário na atividade prática e política da classe trabalhadora, cujas demandas efetivas a direcionam para o uso da razão que possa captar as contradições efetivas do real, desesperadamente escamoteadas pelo liberalismo e pelo fascismo, sob ameaça de que os trabalhadores, imbuídos da apreensão racional do movimento tendencial do mundo burguês, poderiam encontrar por este caminho a correta direção para a sua insatisfação, gerando um movimento antissistêmico que levaria finalmente a uma nova ordem. Desta vez, uma ordem para si.

A luta deste movimento popular, que apreende razão em seu sentido concreto, não pode ter uma perspectiva iconoclasta de progresso. Existe certa visão pequeno-burguesa dentro da esquerda que precisa ser repelida. Profundamente eclética, se veste com roupagens tanto mais suntuosas quanto mais for vazia; quanto mais se mascara de crítica e revolucionária, tanto maior perigo que representa para as massas trabalhadoras cuja revolta ainda é confusa (Cf. idem, 2010a, p. 60). A concretização do progresso não pode considerar toda inovação cultural indiscutivelmente revolucionária e toda obra do passado um peso morto. Tal concepção seria uma forma niilismo que nutre da mesma origem da desrazão fascista (Cf. idem, 2007b, p. 64-65). A suprassunção dos elementos científicos, culturais e artísticos produzidos pela humanidade sob o jugo das sociedades pré-capitalistas e capitalista exige profundas rupturas, mas seria igualmente retrógrado não incluir o fator de conservação necessário para que subsistam todos os elementos mais avançados promovidos nas sociedade de classes (Cf. KONDER, 2013, p. 68). Como nos lembra Marx, algo que contribui para a atual decadência da cultura dominante é justamente o fato de que

\footnotetext{
A burguesia tinha a noção correta de que todas as armas que ela havia forjado contra o feudalismo começavam a ser apontadas contra ela própria, que todos os recursos de formação que ela havia produzido se rebelavam contra a sua própria civilização, que todos os deuses que ela havia criado apostataram dela. Ela compreendeu que todas as assim chamadas liberdades civis e todos os órgãos progressistas atacavam e ameaçavam a sua dominação classista a um só tempo na base social e no topo político, ou seja, que haviam se tornado "socialistas". Nessa ameaça e nesse ataque, ela desvendou acertadamente o segredo do socialismo, cujo sentido e tendência ela avaliou com mais justeza do que o próprio assim chamado socialismo é capaz de fazer a seu respeito [...]. (MARX, 2011, p. 80)
}

Embora tais elementos culturais e a própria razão, quando envolvida no movimento efetivo do real, estejam dispostas mais favoravelmente a luta da classe trabalhadora, tal tendência não é suficiente 
para que a sociedade transite para uma outra ordem. No livro A vida de Galileu, de Brecht, há um diálogo entre o astrônomo e um jovem monge, que o pergunta se ele não acreditaria que a verdade que ele tanto gostaria que prevalecesse, se fosse mesmo verdade, acabaria se impondo, independentemente da atuação das pessoas. Convicto, Galileu responde ao pequeno religioso que a verdade só se afirma na medida em que nós a afirmamos. A vitória da razão só pode ser a vitória das pessoas razoáveis (Cf. BRECHT, 1991, p. 121). Tal perspectiva lembra Marx, em sua introdução à Crítica à Filosofia do direito de Hegel, quando afirma que "a arma da crítica não pode, é claro, substituir a crítica da arma, o poder material tem de ser derrubado pelo poder material, mas a teoria também se torna força material quando se apodera das massas" (MARX, 2013, p. 157). Assim, a razão, para que seja revolucionária, precisa permear efetivamente as massas, em seu movimento pela emancipação humana.

O Humanismo abstrato subsistente no liberalismo, em sua manifestação mais avançada, até poderia elogiar o jacobinismo em seus ideais, mas o repudia pelos seus métodos (Cf. LUKÁCS, 2007c, p. 46). A perspectiva da ordem, ainda que em suas manifestações mais radicais, não rompe com o utopismo, tornando-se incapaz de negar o fascismo e dar soluções efetivas para as demandas reais da população. Sem o combate firme ao fascismo, o humanismo capitula frente a extrema-direita, cuja inescrupulosidade permite qualquer artimanha para alcançar os seus objetivos.

Por sua vez, o humanismo concreto não se contenta com formalismos. Compreende a necessária articulação entre indivíduo e gênero para a conformação do gênero humano para si, não como uma perspectiva utópico-mental, mais como horizonte a ser conquistado apenas com a superação material dos entraves impostos pelo modo de produção capitalista (Cf. idem, 2007a, 240-243). Deste modo, tal versão da perspectiva humanista aprendeu com as Teses sobre Feuerbach, que advogam que a terrena família é revelada como o mistério da Sagrada da família, que deve ser prática e teoricamente é eliminada (Cf. MARX, 2009, p. 120).

Portador de tal humanismo, Lukács é categórico ao estabelecer a necessidade do partido comunista - vanguarda revolucionária do proletariado - exercer o seu papel de entusiasmar as massas e organizar a sua revolta contra o fascismo. Com o partido, pode ser realizada a canalização das energias contidas nas insatisfações proletárias espontâneas na direção que possa efetivamente realizar o seu projeto de classe (Cf. LUKÁCS, 2014, p. 80, 168-169).

As sementes do fascismo, subsistentes graças ao auxílio velado dos liberais, só podem ser combatidas com a transição que supere a atual configuração da democracia como poder regido por "duzentas famílias". Somente quando traduzirmos a democracia em seu sentido autêntico, como poder popular, como capacidade de controle político efetivo do povo trabalhador sobre os rumos da sociedade, a ameaça fascista se extinguirá (Cf. idem, 2007c, p. 50-51).

\section{Referências:}

BRECHT, B. A vida de Galileu. In: Teatro completo-volume 6. Rio de Janeiro: Paz e Terra, 1991, p. 51-170. 
ENGELS, F. Carta a Schmidt 5 de agosto de 1890. In: MARX, K; ENGELS, F. Obras escolbidas - volume 3. São Paulo: Alfa-Omega, 1961c. p. 282-284.

KONDER, L. Introdução ao fascismo. Rio de Janeiro: Graal, 1977.

KONDER, L. Os marxistas e a arte. São Paulo: Expressão Popular, 2013.

LUKÁCS, G. As bases ontológicas do pensamento e da atividade do homem. In: O jovem Marx e outros escritos de filosofia. Rio de Janeiro: Editora UFRJ, 2007a, p. 225-245.

LUKÁCS, G. As tarefas da filosofia marxista na nova democracia. In: O jovem Marx e outros escritos de filosofia. Rio de Janeiro: Editora UFRJ, 2007b, p. 55-87.

LUKÁCS, G. Concepção aristocrática e concepção democrática do mundo. In: O jovem Marx e outros escritos de filosofia. Rio de Janeiro: Editora UFRJ, 2007c, p. 25-53.

LUKÁCS, G. Conversando com Lukács. São Paulo: Instituto Lukács, 2014.

LUKÁCS, G. Existencialismo ou marxismo. São Paulo: Senzala, 1967.

LUKÁCS, G. Marx e o problema da decadência ideológica. In: Marxismo e teoria da literatura. São Paulo: Expressão Popular, 2010, p. 51-103.

LUKÁCS, G. Para uma ontologia do ser social II. São Paulo: Boitempo, 2013.

MARX, K. 18 de brumário de Luís Bonaparte. São Paulo: Boitempo, 2011.

MARX, K. Crítica da filosofia do direito de Hegel. São Paulo: Boitempo, 2013.

MARX, K. Teses sobre Feuerbach. In: A ideologia alemã. São Paulo: Expressão Popular, 2009, p. 117-126.

MARX, K; ENGELS, F. A ideologia alemã. São Paulo: Expressão Popular, 2009.

MISES, L. Liberalism. Indianapolis: Liberty Fund, 2005.

\section{Notas:}

1 PPGF UFBA. Professor de Filosofia na rede estadual de educação básica na Bahia. Licenciado em Filosofia pela Universidade Federal da Bahia e mestrando no Programa de Pós-Graduação em Filosofia da mesma instituição. ORCID: https://orcid.org/0000-0002-2247-4632 Email: andrefbrandao96@gmail.com

2 O uso da palavra de ordem "Brasil acima de tudo", em estreita correlação com o grito nazista Deutschland über alles, é sintomático.

3 Até mesmo os atuais paladinos do liberalismo puro e da luta 'anti-estado', como são os membros da chamada escola austríaca, contribuíram política e ideologicamente para governos fascistas, como foi o caso do economista Ludwig Von Mises. Antigo membro do governo fascista de Dollfuss na Áustria, Mises afirma em seu livro liberalismo que "não se pode negar que o fascismo e movimentos congêneres, ao tentar estabelecer ditaduras, estavam cheios de boas intenções e sua intervenção foi, momentaneamente, a salvação da civilização europeia. O mérito que o fascismo conquistou para si viverá eternamente na história. [...] O fascismo foi um improviso emergencial.” (MISES, 2005, p. 30, tradução nossa). 